http://dx.doi.org/10.12795/PH.1990.v05.i01.04

\title{
Operaciones de «Repérage» en el texto literario
}

La teoría de la enunciación considera el enunciado como el resultado de un acto enunciativo, es decir de una serie de operaciones metalingüísticas efectuadas sobre nociones. Entre estas operaciones, algunas consisten en «repérer» algo con relación a algo o a alguien. Son las operaciones de «repérage» de las que vamos a tratar.

Ya es antigua la idea de que existen diferentes tipos de textos (o de discursos) que se distinguen entre sí por reglas implícitas que rigen el empleo de ciertas formas gramaticales (como el uso de determinados tiempos verbales, pronombres personales o adverbios de tiempo). En un artículo titulado «Les relations de temps dans le verbe français» ${ }^{1}$, E. Benveniste introduce ya la oposición entre «discours» e «histoire», recogida y precisada desde entonces por otros autores ${ }^{2}$. Las diferencias entre tipos de discurso (entendiendo discurso ahora como «construcción textual») no son, por tanto, exclusivamente de orden "estilístico», sino que conciemen al propio funcionamiento de las categorías lingüísticas (incluyendo el problema de la atribución de los valores referenciales).

En efecto, recogiendo la oposición establecida por Benveniste entre «discours»e «histoire», podemos distinguir diferentes tipos de construcción textual en función de las marcas, de las huellas, de las operaciones de «repérage» que comportan. Benveniste da el nombre de «discours» a los textos que contienen marcas de operaciones de «repérage»

\footnotetext{
${ }^{1}$ Artículo publicado en 1959 y recogido en Problèmes de linguistique générale 1, (Paris: Gallimard, 1966), pp.237-250.

${ }^{2}$ Cf. S. Y Kuroda, «Réflexions sur les fondements de la théorie de la narration», en Langue, discours, société. Pour Emile Benveniste, ed. Julia Kristeva, Jean-Claude Mllner, Nicolas Ruwet (Paris: Seuil, 1975), pp. 260-293; L. Danon-Boileau, Produire le fictif (Paris: Klincksieck, 1982); etc.
} 
con relación a la situación de enunciación; y define como «histoire» los textos que no comportan dichas marcas.

Danon-Boileau reprocha a estas nociones de «discours» y de «histoire» el hecho de no ser más que «des hypostases artificielles de deux types de repérages»; y la distinción entre tipos de discurso es rechazada con el argumento de que todos los textos utilizan ambos tipos de operaciones. Es cierto, en efecto, que un texto caracterizado como «discours» comporta también operaciones anafóricas. Sin embargo, existen textos de «histoire» que no contienen marcas de operaciones deícticas. Por otra parte, aunque un texto pueda comportar a la vez «repérages» deícticos y «repérages» nodeícticos (anafóricos o no -volveremos sobre ello-), no deja de tratarse de dos modos diferentes de construcción de los valores referenciales. La distinción entre «discours» e «histoire» es, de hecho, de orden cualitativo y no cuantitativo.

Por otra parte, no podemos considerar «l'histoire» como el término no marcado de la oposición «discours-histoire», es decir como si se tratase de «discours» menos las marcas de la enunciación. Las marcas de la enunciación no son algo que se añada o no al enunciado, en mayor o menor medida. Si «l'histoire» no está determinada por referencia a la situación de enunciación, lo está, sin embargo, por otras operaciones.

Por otra pare, conviene precisar que todas las operaciones no-deícticas no son anafóricas. Existen determinaciones de tipo contextual que no son anafóricas propiamente dichas: por ejemplo las relaciones de «temps relatif», donde un proceso es «repéré» como anterior o posterior a otro proceso del contexto. Un término anafórico, entendiendo «anáfora» en sentido estricto, tendría el mismo valor referencial que el término al que representa, y no es éste el caso.

Siguiendo a C. Kerbrat-Orecchioni ${ }^{4}$, cabría distinguir tres tipos de mecanismos referenciales: referencia absoluta, referencia relativa al contexto lingüístico o cotexto y referencia relativa a la situación de enunciación o referencia deíctica. En el siguiente texto:

(1) «Le lendemain, Marcelle revint à la même place pour écouter et se souvenir. Elle portait dans ses bras une poupée que la mère de Bigua lui avait donnée».

(Supervielle. Le voleur d'enfants).

une poupée representa un caso de referencia absoluta, en la medida en que para denominar $\mathbf{x}$ basta tomar en consideración dicho objeto $\mathbf{x}$, sin la aportación de ninguna información anexa.

Este tipo de términos son considerados por esta autora como « autodéterminés». En esta primera categoría habría que incluir también las fechas y los nombres propios, tanto de lugar como de persona.

Sin embargo, en el caso de la mère de Bigua, la elección del término mère para designar $\mathbf{x}$, implica que el locutor tiene presente, además del propio objeto $\mathbf{x}$, una persona $\mathbf{y}$, tomada como elemento de referencia. De la misma manera, para interpretar

${ }^{3}$ L. Danon-Boileau, op. cit., p. 89.

${ }^{4}$ L'énonciation. De la subjectivité dans le langage (Paris: Armand Colin, 1980). 
esta expresión, no será posible dar un contenido referencial preciso a la palabra mère, si no se tiene en cuenta la relación $\mathbf{x y}$, es decir que el significante mère no está vinculado o ligado de manera absoluta al objeto $\mathbf{x}$, ya que este mismo objeto podría ser designado en el texto con otras expresiones como la belle mère de Desposoria, la grand-mère d'Antoine, etc. Su elección depende del elemento y seleccionado, pero no depende, al menos no directamente, de la situación de enunciación. Entrarían en esta categoría, además de los términos de parentesco, adverbios y expresiones como le lendemain, la veille, loin, près, au sud, au nord, devant, derrière, à droite, à gauche, etc.

Cuando el elemento y que sirve como punto de referencia no viene explicitado en el cotexto inmediato del término relacional, tenemos dos posibilidades: 1) el término y elidido es un elemento del cotexto «large»: así le lendemain del ejemplo citado nos remite al día en que estaban sucediendo los acontecimientos narrados, y designa «el día siguiente a ese día». De la misma manera, si encontramos en un texto «Il habitait au sud», y se está hablando de París, el elemento y sobreeentendido sería justamente dicha ciudad ("Il habitait au sud de Paris»). 2) Cuando en el cotexto ningún elemento puede funcionar como término y, habrá que identificar y con un elemento de la situación de enunciación: Ej. «C'est un ami» (à moi), «Approche» (d'ici), «ll habite à côté» (d'ici), etc.

Volviendo al texto citado, los pronombres elle y lui que en él aparecen, representan otro caso de referencia contextual, esta vez anafórica. Son términos que reciben su significación de otro término contenido en el mismo texto y al que representan, en este caso Marcelle. La diferencia entre los términos anafóricos («représentants») y los relacionales estriba en que estos últimos tienen un sentido autónomo y un «dénoté» distinto de $\mathbf{y}$, mientras que los primeros toman su contenido semántico y referencial de y, que sería su antecedente («interprétant»).

El término «anafórico» presenta el inconveniente de ser un tanto ambiguo. Algunos autores lo utilizan como sinónimo de «representación», sin hacer más distinciones. Otros lo reservan para los casos en que el representante remite al contexto anterior, y distinguen entre representación por anáfora y representación por anticipación o catáfora. M. Maillard ${ }^{5}$ reune ambos tipos de representación bajo el nombre de «diaphore». Otros autores, entre ellos J.C. Milner ${ }^{6}$ y F. Corblin ${ }^{7}$ defienden un concepto más amplio de anáfora, precisando que el segmento lingüístico anterior, indispensable para que haya anáfora, no tiene que remitir necesariamente al mismo referente que la expresión anafórica. Correferencia y anáfora no coinciden forzosamente. Así, si una persona le dice a otra: «La plante que tu $\mathrm{m}$ 'as offerte a crevé», y ésta le responde: «ça ne m'étonne pas. Cette plante, il fautl'arroser très souvent", cette plante remite en efecto a la primera ocurrencia de plante, y sin embargo, no es una expresión correferencial de esta ocurrencia. Cette plante se refiere a la especie en general, mientras que la primera ocurrencia de «plante» tiene un referente mucho más preciso («la plante que tu m'as offerte»). Desde este punto de vista, la única condición para que una expresión

5 «Essai de typologie des substituts diaphoriques», Langue Française, 21 (1974), pp. 55-71.

${ }^{6}$ Ordres et raison de langue (Paris: Seuil, 1982).

7 «Sur la notion d'anaphore», Revue Québécoise de linguistique, vol. 15, 1 (1985), pp. 173-195. 
referencial pueda ser considerada anafórica, es que las informaciones necesarias para la localización del objeto designado por ella, se hallen en el entorno textual de dicha expresión. Una concepción amplia de la anáfora podría llegar a incluir expresiones que hemos caracterizado anteriormente como «relacionales».

El tercer tipo de referencia, es decir la referencia deíctica, la encontramos en un ejemplo como «J'habite ici» o «Tu partiras demain», donde la elección de la unidad significante apropiada y su interpretación referencial se realizan teniendo en cuenta datos particulares de la situación de enunciación. Habría que precisar que esta referencia puede llevarse a cabo mediante unidades con sentido deíctico, es decir con deícticos propiamente dichos, o mediante unidades con uso deíctico, es decir, unidades que entre otros empleos, son susceptibles de un uso deíctico: así, el artículo definido en el enunciado «donne-moi le crayon», remitiendo a un referente presente en la situación de enunciación. Estaríamos, en efecto, ante un caso de referencia deíctica. Sin embargo, a pesar de la relación evidente, no hay que confundir «uso deíctico» y «sentido deíctico». Así, el artículo definido es susceptible de usos que no son ni deícticos ni anafóricos, pudiendo referir a entidades ausentes de la situación de enunciación y del contexto lingüístico: ej. «Il est bon de dormir la fenêtre ouverte».

Este tipo de uso no puede darse nunca en los deícticos propiamente dichos, que pueden ser definidos como expresiones que remiten a un referente cuya identificación sólo puede lograrse teniendo en cuenta el entorno espacio-temporal de su ocurrencia. Esta formulación, -conviene precisarlo-, no dice que el referente deba estar presente en el entorno espacio-temporal de la osurrencia en cuestión. Puede darse, evidentemente, una presencia efectiva del referente en la situación de enunciación, pero no es indispensable. La definición que hemos dado, estipula únicamente que la identificación del referente requiere la consideración de las relaciones espacio-temporales de la ocurrencia. Y estas relaciones pueden ser inmediatas -en caso de presencia efectiva del referente en la situación de enunciación- o diferidas -recordemos «l'exophore mémorielle» de Fraser y Joly ${ }^{8}$. Así, una amiga podrá dirigirse a otra cuya hija acaba de fugarse de casa, diciéndole: «Cette fille va avoir ta peau. Elle ne te cause que des ennuis», sin que ésta esté presente en la situación de enuncianción y sin que hayan hablado antes de la chica en cuestión (por lo que queda excluída la anáfora)".

De la misma manera, cuando en una situación de discurso un demostrativo como ceci designa un objeto de la situación de enunciación, mediante un gesto ostensivo, como un dedo señalando al objeto en cuestión, no puede decirse que la ocurrencia de ceci se encuentre directamente en relación con el propio referente, sino con elementos intermediarios del entorno situacional extralingüístico que conducen a la indentificación de dicho referente. No hay relación factual o espacio-temporal directa entre el objeto designado y la ocurrencia del deíctico utilizado para designarlo. Sin el gesto, el interlocutorno podría localizar el referente. Lo que permite localizar el objeto designado

8 «Le système de la deixis. Esquisse d'une théorie d'expression en anglais», Modeles Linguistiques, T. I, fasc. 2 (1970), pp. 97-151.

${ }^{9}$ Paralelamente, las relaciones anafóricas entre el representante y el antecedente pueden ser directas caso de correferencia- o diferidas -ausencia de correferencia-. 
es, en definitiva, el gesto de señalamiento que acompaña la ocurrencia del deíctico utilizado.

De esta manera, podríamos hacer una distinción entre deícticos directos o transparentes cuya ocurrencia se encuentra siempre en relación espacio-temporal directa con el referente (sería el caso de los deícticos personales, por ejemplo) y deícticos opacos o indirectos, cuya función consiste exclusivamente en indicar que su ocurrencia está en relación espacio-temporal con elementos del entorno situacional que permiten la identificación del referente (o del entorno textual, en caso de anáfora). Es el caso de los demostrativos.

Dos son, por tanto, los tipos de «repérage» (si excluímos la referencia absoluta) que podemos encontrar en los textos literarios: «repérage» de los términos o de los procesos con relación a la situación de enunciación y «repérage» con relación al contexto lingüístico. Y cada uno de estos dos tipos de función referencial predomina en un tipo de texto. En los textos dialogados, por ejemplo, predominará el «repérage» por deíxis, ya que los interlocutores se encuentran en una «situación» y se refieren a las coordenadas espacio-temporales de la misma, mientras que en los textos narrativos predominará el «repérage» por anáfora o si se prefiere «repérage» contextual.

Dentro de la categoría lógico-literaria del «récit» podríamos empezar distinguiendo, por un lado, el texto narrativo en tercera persona, que es, por naturaleza un discurso «non daté», caracterizado esencialmente por la ausencia de origen espacio-temporal; y por otro lado, el relato en primera persona de los diarios, novelas epistolares, autobiografías, etc.

En los primeros -relatos en tercera persona-, las operaciones de "repérage» se realizan siempre partiendo del propio texto, es decir tomando como punto de referencia elementos del entorno textual, tanto anterior como posterior (anáfora-catáfora):

(2) «Le lendemain, elle loua un modeste équipage et se fit conduire à la cabane du prince solitaire. Elle poussa timidement la porte (...); elle s'agenouilla, avec un humble petit rire, pour s'excuser d'être là. (M. Yourcenar: Nouvelles Orientales).

Por el contrario, los segundos son textos «datés» con relación a la situación de enunciación del narrador, y que pueden utilizar, por tanto, deícticos, tanto personales, comos espaciales y temporales, usentes casi siempre de los relatos en tercera persona:

(3) «Cette nuit je n'ai pas pu dormir. Le mistral était en colère, et les éclats de sa grande voix m'ont tenu éveillé jusqu'au matin (...) Cela m'a rappelé tout à fait mes belles insomnies d'il y a trois ans» (A. Daudet: Lettres de mon moulin).

(4) «C'etait dans cette île enchantée qu'avant d'avoir un moulin j'allais m'enfermer quelquefois (...) Ce que je faisais? Ce que je fais ici, moins encore». (A. Daudet:Ibid) 
(5) «Vous verrez, ma belle amie, en lisant les deux lettres ci-jointes, si j'ai bien rempli votre projet. Quoique toutes deux soient datées d'aujourd'hui, elles ont été écrites hier, chez moi, et sous mes yeux» (9 sept. 17**) (Laclos: Les liaisons dangereuses)

(6) «16 mai. - Je suis malade, décidément! Je me portais si bien le mois demier! (...)

3 juillet. - J'ai mal dormi; certes, il y a ici une influence fiévreuse, car mon cocher souffre du même mal que moi. En rentrant hier, j'avais remarqué sa pâleur singulière». (Maupassant: Le Horla).

Todos ellos son ejemplos de textos «datés», textos que se sitúan en el plano de enunciación que Benveniste denomina «discours», y que contienen diferentes unidades deícticas: así, los tiempos verbales (passés composés, presentes, y futuros, tiempos excluídos de los textos tipo «histoire»); los deícticos personales (je remitiendo a la persona del enunciador y vous a la del destinatario -la Marquise de Mertenil, en (5))-, así como los correspondientes posesivos (mes belles insomnies en (3), ma belle amie, mes yeux y votre projet en (5), mon cocher en (6)); los deícticos espaciales (ici, remitiendo en (4) al molino desde donde escribe el narrador y en (6) al lugar donde vive y que incluye al de la enunciación); y finalmente, deícticos temporales (cette nuit y il y a trois ans en (3), aujourd' hui en (5), le mois dernier en (6), hier en (5) y en (6)). Es evidente que todas las expresiones deícticas que aparece en estos ejemplos permanecen indisolublemente ligadas a la fecha real o convencional asociada al texto del que forman parte: Le mois dernier en (6) hace referencia al mes de abril, porque toma como punto de referencia el mes de mayo; aujourd' hui y hier en (5) remiten al 9 y al 8 de septiembre respectivamente, ya que la carta está fechada el 9 de septiembre; hier en (6) designa el 2 de julio, puesto que aparece en un texto redactado el 3 de julio. Si, por una u otra razón, esta fecha es desconocida por el destinatario, hay pérdida de información, pero la naturaleza del discurso sigue siendo la misma. Todas estas expresiones deícticas suelen estar excluídas de los textos que se sitúan en el plano de «l'histoire».

Decimos «suelen» porque hemos comprobado que esta ausencia de origen temporal no impide, en ocasiones, el uso de deícticos temporales en la narración de tipo «histoire», donde en efecto pueden aparecer sin perder su identidad y conservando, por tanto, su significación fundamental. Este uso afecta, sin embargo, a su funcionamiento, ya que no pueden ser interpretados como en un «discours daté» ${ }^{10}$.

Por otra parte, hay que tener en cuenta la existencia de textos no homogéneos, donde se da una imbricación de «repérages» deícticos y contextuales. Es el caso de los textos caracterizados por la correlación sistemática de una categoría deíctica y de una categoría no deíctica, por ejemplo, la $3^{\mathrm{a}}$ persona + el presente, o la $1^{\mathrm{a}}$ persona + el passé simple.

Para dar cuenta de ello, hay que tener presente que las diferentes operaciones de «repérage» no son independientes unas de otras. Una misma forma lingüística es

10 Cf. María Muñoz, «funcionamiento de los deícticos temporales en la narración», Philologia Hispalensis, vol. III (1988), pp. (95-102). 
susceptible de cobrar valores diferentes, y puede ser interpretada como la marca de operaciones distintas. Una misma forma puede remitir a la instancia de enunciación o ser determinada por el contexto linguístico. Es el caso de los demostrativos, que pueden funcionar como deícticos o como anafóricos. Habría que determinar lo que en el contexto selecciona un valor u otro. A veces incluso las dos interpretaciones son compatibles: así, en ocasiones, es casi imposible decidir si se trata de una deíxis memorial o de una referencia contextual:

(7) «(...) quand j'habitais le Phare des Sanguinaires, là-bas, sur la côte corse, à l'entrée du golfe d'Ajaccio... » (A. Daudet: Lettres de mon moulin).

En este ejemplo, là-bas es susceptible de dos interpretaciones: puede considerarse un representante catafórico, que remite a los segmentos «Sur la côte corse, à l'entrée du golfe d'Ajaccio», o un deíctico que remite a un lugar alejado del enunciador, pero que éste tiene en mente. En este caso ambas interpretaciones no se excluyen.

También puede darse el caso de que elementos lingüísticos, que funcionan normalmente como deícticos, es decir que son determinados por referencia a la situación de enunciación, no puedan tener, en ciertos contextos, más que un valor determinado por el entorno lingüístico. En efecto, cuando la correlación yo-tu / presente / adverbios deícticos se rompe, un término normalmente deíctico puede llegar a perder totalmente su valor deíctico: por ejemplo, el presente asociado a la tercera persona y a adverbios no deícticos toma un claro valor aorístico:

(8) «Antoine voit entrer sa mère dans la chambre. Elle le considère comme elle n'avait jamais fait jusqu'à alors (...) Elle s'assied sur le bord du lit, ses yeux émerveillés se tournent vers lui. Elle garde le silence comme si elle avait complètement désappris de parler» (J. Superville: Le voleur d'enfants).

Del mismo modo, en los relatos en $1^{a}$ persona que utilizan como tiempo de la narración el «passé simple», el pronombre personal je pierde su valor deíctico. Estos textos no pueden considerarse como «discours», ya que los acontecimientos narrados no toman como punto de referencia la situación de enunciación del narrador. Prueba de ello es que son adverbios no-deícticos los que suelen aparecer en este tipo de textos:

(9) «L'année précédente, je n'avais rien écrit» (S. De Beauvoir: La Force de l'âge).

(10) «La première (lettre) m'arriva dès le surlendemain de son départ»

Le surlendemain y l'année précédente son expresiones que sitúan los acontecimientos con relación a otros acontecimientos y nunca con relación al contexto situacional de enunciación.

En este tipo de textos, la historia del YO es referida como lo sería la historia de otra persona. El YO que escribe y el YO del que se habla no son el mismo. El YO que escribe se manifiesta, por ejemplo, en los pasajes de «discours» que aparecen ocasionalmente en el cuerpo de la narración: 
(11) «Aujourd'hui, j'ai peine à concevoir comment je l'abandonnai frissonnante...» (S. de Beauvoir: La force de l'âge).

La distinción es neta entre el «je» de ahora y el «je» de entonces. Para Todorov, «le "je" qui peut y apparaître (dans le discours ne contenant pas de références à la situation d'énonciation) n'est pas le «je» qui parle (bien qu'il s'agisse de la même personne, c'est-à-dire du même nom propre); c'est un «je» à valeur indicielle affaiblie» ${ }^{11}$.

Este tipo de textos ofrece la posibilidad de pasar facilmente del «discours» a «l'histoire», alternando ambos planos de enunciación. En efecto, Benveniste no define «le discours» y «l'histoire» como «tipos de discurso», sino como «planos de enunciación», y añade que «dans la pratique on passe de l'un à l'autre instantanément (...) Le propre du langage est de permettre ces transferts instantanés» ${ }^{12}$. Por lo tanto, no debemos extrañarnos de encontrar textos no homogéneos. Un ejemplo claro de este paso de «l'histoire» al «discours» son los textos que contienen un «discours rapporté». Si consideramos el «discours rapporté» como un tercer tipo de enunciación, como el propio Benveniste propone ${ }^{13}$, vemos que siempre aparece incluído en un contexto que constituye otro plano de enunciación («discours» 0 «histoire»).

(12) «Maman est partie d'un éclat de rire, en me disant: «Eh bien! Qu' avez-vous? Asseyez-vous et donnez votre pied a Monsieur». En effet, ma chère amie, le monsieur était un cordonnier» (Laclos: Les liaisons dangereuses).

(13) «Le lendemain, en rentrant, il la contempla d'un oeil finaud, et ne put à la fin retenir cette phrase: Quel entêtement tuas quelquefois! J' ai étéd Barfeuchères aujourd' hui...» (G. Flaubert: Madame Bovary).

(14) «Le lendemain, il la pria de lui jouer encore quelque chose (...) Et Charles avoua qu'elle avait un peu perdu (G. Flaubert: Ibid).

(12) Es un ejemplo de discurso reproducido en estilo directo (DD) e inserto en un texto tipo «discours». En (13), el discurso directo se halla incluído en un texto de tipo «histoire». Y finalmente (14) presenta dos reproducciones en estilo indirecto (DI) dentro de un texto de tipo «histoire».

Un tipo de discurso o de construcción textual podrá definirse, por tanto, como constituído por un plano de enunciación, o por la imbricación de varios planos de enunciación, como es el caso de la mayoría de la novelas, que introducen, ya se en DD, DI o DIL los propósitos de los personajes.

Los diálogos introducidos por el narrador para reproducir en estilo directo las palabras de los personajes, comportan operaciones de «repérage» por deíxis. El narrador

11 «Freud sur l'énonciation», langages, 17 (1970), p. 40.

12 «Les relations de temps dans le verbe français», op. cit, p.242.

${ }^{13}$ Ibid 
sitúa al lector en la coordenada espacio-temporal de los personajes y éste dirige mentalmente su atención al espacio-tiempo reproducido, al que lo traslada la ficción. El enunciado «rapporté» no tiene como origen de las operaciones de «repérage» al narrador primario, sino que los tiempos y las referencias deícticas -al igual que las modalidades, por otra parte- remiten al narrador «rapporté». De todas formas, un discurso reproducido en estilo directo, disociado doblemente -por el hecho de ser un texto escrito y por el hecho de ser «discours rapporté»- de la situación de enunciación en la que ha sido producido, requiere a veces una verbalización de los datos de la situación que perrnita al lector reconstruir el valor referencial de los términos deícticos en él empleados, y que sin este requisito, no podrían interpretarse:

(15) «En passant devant la chapelle, elle regarda attentivement le moine, qui en fut dérangé dans ses oraisons. (...) -Et que fais-tu ici, vieux moine?» (M. Yourcenar: Nouvelles Orientales).

Ici, en este ejemplo, puede ser interpretado gracias a la verbalización de un dato situacional, en este caso el lugar en que se produce la enunciación («devant la chapelle»). Del mismo modo, en (13) aujourd' hui remite al día siguiente a aquel en que tuvieron lugar los acontecimientos antes narrados y esto lo sabemos por la aparición en el contexto de la expresión le lendemain.

En la reproducción en estilo indirecto, sin embargo, los tiempos verbales, las personas y ciertos adverbios deícticos sufren modificación con respecto al discurso original. En el enunciado "Charlotte dit qu'elle partirait le lendemain», elle y le lendemain son transposiciones de lo que en el discurso original sería je y demain (Charlotte dit: «je partirai demain»). La noción de «transposición» significa, en realidad, la alteración del discurso primitivo, debido a un cambio de puntos de referencia u origen. En el discurso indirecto, los puntos de referencia no proceden del narrador «rapporté», contrariamente a lo que sucede en el DD. ¿Quién los proporciona en ese caso? ¿El narrador primario? No siempre. En el ejemplo que acabamos de ver, el significado de le lendemain no puede ser «repéré» con relación a un narrador y su situación de enunciación, sino con relación a un enunciado, el enunciado primario. La transposición consiste, pues, en un cambio de sistema de referencia. La operación de «repérage» no es la misma: se pasa de un «repérage» por deíxis a un «repérage» contextual. El punto de referencia, «le repère», no es ya una situación de enunciación, sino un segmento de enunciado. La aparición del narrador «rapporté» no provoca una nueva situación de enunciación. Es lo que explica que en el caso en que el discurso primario sea un discurso «daté», los tiempos, las personas y los adverbios deícticos puedan ser definidos con relación al punto de referencia que constituye la situación de enunciación del enunciador primario. Así en el enunciado «Paul m'a dit hier qu'il viendrait demain» (que correspondería a: «Paul m'a dit hier: j'irai après-demain), demain toma como punto de referencia la enunciación del enunciador primario y no la de Paul. Igualmente habría que señalar el cambio de ver'bos deíctivos -venir en lugar de aller-, una prueba más del cambio de «repère» que se ha producido.

Por tanto, en la reproducción es estilo indirecto, habría que distinguir dos casos: 
1) El discurso primario es un discurso «daté» (un diario o una novela epistolar, por ejemplo): los deícticos del DD, «repérés» con relación a la situación de enunciación del enunciador «rapporté», pasan a deícticos referidos en este caso a la enunciación del narrador primario.

2) El discurso primario es un discurso «non daté» (un relato en tercera persona): los deícticos del DD sufren un cambio de estatus que los convertirá en elementos anafóricos, «repérés» con relación al enunciado del narrador primario.

El tercer tipo de «discours rapporté» es el llamado «Estilo Indirecto Libre» (DIL). Como en el caso del DI, el discurso reproducido en estilo indirecto libre pierde su forma original para integrarse en el discurso del narrador primario, del que en ocasiones es casi imposible disociar. El DIL es un fenómeno de heterogeneidad enunciativa que, a diferencia del DD y el DI, puede no presentar marcas lingüísticas o tipográficas claras. Fuera de contexto, nada permite a veces conferir de manera segura a un enunciado el estatus de DIL.

Esto viene ligado a la propiedad que tiene de reproducir propósitos dejando oir intimamente mezcladas dos voces diferentes, dos enunciadores, dos narradores. De ahí que sean frecuentes las ambigüedades que conciernen al origen y al soporte de las operaciones enunciativas -no sólo las operaciones de «repérage» que nos ocupan, sino también las de modalización. ¿A qué narrador atribuir el DIL? No puede ser el enunciador del discurso original, ya que las personas y los tiempos verbales no toman como punto de referencia la enunciación original. Tampoco puede ser el narrador primario, ya que el DIL comporta marcas evidentes de la enunciación original (modalidades, deícticos espaciales y temporales...).

EI DIL manifiesta así una disociación entre narrador y sujeto de conciencia. Los deícticos espaciales y temporales (así como las modalidades) son asumidos por la conciencia de un sujeto que no es más que un personaje de narración, y en ningún caso un YO, un locutor:

(16) «Paul s'accouda au balcon. Quel soulagement! Aujoud'hui tout était prêt, il allait enfin s'installer»

Aujourd' hui, deíctico que remite al presente del personaje, aparece como contemporáneo de un imperfecto impuesto por el contexto narrativo. Esta asociación resultaría imposible en un DD.

Por otra parte, el DIL supone una disociación entre la función de comunicación del lenguaje y su función de expresión. Para que haya comunicación, es necesario un YO que se dirija a un TU. El DIL se limita a la función de expresión, admitiendo elementos expresivos muy diversos, a excepción de los que remiten a la relación YO-TU. Es por lo que no encontramos en el DIL vocativos ni imperativos. En el DIL queda también excluida la presencia de deícticos personales anclados en la situación de enunciación del narrador rapporté. Pueden encontrarse deícticos de $1^{\mathrm{a}}$ y $2^{\mathrm{a}}$ persona, pero nunca serán los interlocutores del discurso «cité»:

(17) Marie m'aborda: voulait-on vraiment la blesser en lui parlant de Paul devant moi? 
En este enunciado, moi no se entiende si no es en relación con la enunciación primaria. En efecto, los deícticos de $1^{\mathrm{a}}$ y $2^{\mathrm{a}}$ persona sólo quedan excluidos del DIL si constituyen los índices utilizados por el enunicador «rapporté». Si remiten al narrador primario o a su interlocutor, pueden sin duda figurar:

(18) «Il me sauta dessus: j'étais un fils dénaturé, il allait tout vous raconter».

El je del DIL coincide con el narrador primario, y el vous con el destinatario del discurso primario. Este uso es, de todas maneras, poco frecuente, sólo se da en relatos en primera persona. Cuando se trata de un relato en tercera persona donde,tenemos un narrador invisible que no interviene a penas en el desarrollo de lo que cuenta, no encontramos estos usos. En resumen, las expresiones deícticas personales que aparecen en un enunciado «rapporté» en estilo indirecto libre no pueden tener nunca como origen al narrador «rapporté». Pérdida, por tanto, de autonomía de los deícticos personales, así como de los tiempos verbales (utilización de «temps relatifs», propios de «l'histoire»). En este punto coincide con el funcionamiento del DI.

Sin embargo, podemos encontrar adverbios deícticos «repérés» con relación a la enunciación «rapportée» (aujoud' hui en (16), por ejemplo). Esta mezcla de orígenes enunciativos es justamente la característica delDIL. Es un modo de enunciación original basado en la polifonía. En un fragmento de DIL se oyen dos voces, dos puntos de vistas intimamente ligados. Y el lector percibe esta dualidad precisamente por la discordancia que percibe entre ambas voces, discordancia que le impide atribuir todo el enunciado a una sola instancia enunciativa.

Por último, el texto dramático, que puede definirse como la representación dialogada de una acción, es un texto donde el narrador desaparece para dar paso a los personajes que expresan directamente sus pensamientos o sentimientos, «Ce locuteur réel, l'auteur, a disparu dans la fiction même, il s'est dispersé dans les rôles des personnages fictifs (...) La fiction, par là, tout en restant message, acquiert le statut d'un objet relativement autonome...», dice Rainer Warning, hablando del modelo teatral ${ }^{14}$.

Son, por tanto, textos donde predomina un «repérage» por deíxis, anclado en la situación de enunciación de los personajes:

(19) «Andromaque: Oui, si Hector n'était pas là! mais il arrive, Cassandre, il arrive! Tu entends assez ses trompettes...En cette minute, il entre dans la ville, victorieux. Je pense qu'il aura son mot à dire. Quand il est parti, voilà trois mois, il m'a juré que cette guerre était la dernière». (J. Giradoux: La guerre de Troie n'aura pas lieu).

No olvidemos que un texto dramático es un texto para ser representado. La puesta en escena proporciona al espectador los elementos necesarios para interpretar correctamente las expresiones deícticas que aparezcan en el discurso de los personajes. 
Tampoco negamos que en algunos casos las indicaciones del autor, cuando nos enfrentamos al texto escrito y no a la representación de la obra, funcionan para el lector como verbalización de los datos de la enunciación, ayudándolo a reconstruir el valor referencial de algunas expresiones deícticas. Así, el hecho de encontrar, encabezando la intervención de cada personaje, el nombre del mismo, ayuda evidentemente al lector a interpretar los je y los tu/vous que aparecen en la obra. Estas indicaciones desaparecen en la puesta en escena, donde ya no son necesarias.

Hemos intentado demostrar, a lo largo de estas páginas, cómo, para dar cuenta de las diferencias entre las distintas prácticas discursivas, entre las distintas construcciones textuales, la lingüística debe ponerse al servicio de la literatura, permitiéndonos así analizar las diferentes relaciones que se establecen entre enunciado y enunciación, punto de partida indispensable para establecer una tipología de discursos. 